\title{
Optimization approaches of large rail-freight junctions
}

\author{
C. W. Flotzinger \& M. Plasch \\ Department of Transport Logistics, Institute Logistikum, \\ University of Applied Sciences Upper Austria, Austria
}

\begin{abstract}
Rail-freight junctions have the primary role of efficiently moving freight for the domiciled forwarders through interconnections to national and international transport corridors. To fulfil transport demands a holistic view of all relevant infrastructural components (e.g. intermodal facilities, shunting yards) is needed. Intermodal freight hubs use two or more forms of transportation to move goods. Freight yard complexes with their main functional components involving (i) receiving, (ii) switching and (iii) departure yard are directed to ensure transport in individual wagons. That results in a distress, when block trains, intermodal trains and full-load traffic concur within large junctions. Characteristically, large freight junctions are often historically grown, therefore limited in capacity and operationally inefficient. Based on that, the purpose of the project OPTImodal implies to bring different players of one considered junction together, in order to optimize logistics and transport processes and to develop the (cooperative) use of the infrastructural and operating resources on site.

Results comprise the creation of a prototype with various functions implemented: (i) a disposition system for an effective empty wagon handling, (ii) an analysis tool for more efficient handling processes of the shunting yard (e.g. with adjusted time frames for opening hours) and (iii) a tool for reducing bottlenecks within the junction through smoothing the capacities by timely information use. Important manufacturers located at the site or nearby are looking for cost-efficient and operation-effective ways of getting their goods, components and services in and out of the junction. Aspects like an optimized availability of operational resources and a maximized degree of capacity utilization are fundamental to offer competitive transport chains and to gain
\end{abstract}


competitive advantages in the markets. To this end, the developed prototype for analyzing, disposing and planning - lifts modal shift potentials within the junction, supports operation processes and eases infrastructure investment decisions.

Keywords: optimisation and utilisation concepts, sustainability, co-operation, competitive rail-freight transport, rail-freight junction, information and risk management, modal shift.

\section{Introduction}

From today's perspective the challenges in the European rail-freight business are characterized in particular by one crucial fact: shippers more frequently generate products and claim delivery time frames that often can only be partly fulfilled through physical rail-freight transport [1]. However, this is not only because of given system disadvantages of rail-freight transport compared to other modes of transport (primarily the truck) [2]. Above all, there are historically grown provider structures and established monopolistic regulations for system and infrastructure usage - combined with unspecific orientation towards customer demands and non-existent openness to cooperation initiatives - which allow only little advancement in rail-freight services [3].

Especially in rail-freight junctions where the establishment of pre-/oncarriage from/onto other modes of transport, loading, unloading, handling and transport-related storage services needs to be implemented, the requirements for the rail-freight value chain appear very difficult. As multiple stakeholders (shippers, logistics service providers, freight forwarders or operators, etc.) are involved in rail service provision within freight junctions/hubs, there is plenty cooperation and coordination potential.

In the end, rail-freight systems face changing customer requirements [4]. In terms of the rail's system strength - seen as the basis of performance - the following requirements need to be considered:

- Goods should be transported over long distances, as the costs become clearly justified. (Rail freight is lagging behind in terms of that requirement, until now).

- The goods should be transported in high volumes. The higher utilized wagons and trains, the better the fixed costs can be covered (fix cost degression). (An increasing container use, growing numbers in port hinterland transports and the possibility of inter-plant transport or transportation of high volumes within the provider networks of logistics services can be beneficial).

- $\quad$ Rail should carry goods that must be delivered at fixed time frames. (Rail-freight systems offer all necessary logistical requirements - can be integrated into time-dependent logistic transport processes).

In contrast, rail-freight transport - by its very nature - is less suited for domestic transportation or transport of small volumes, mainly because the required network density is not given. Its system drawbacks result from low flexibility due to specified routes and schedules as well as from extended 
transport times in single wagon transport. In addition, the lack of offers relating to wagon tracking, bottlenecks on main transportation routes as well as timeconsuming and costly transshipment activities in combined transports stand for systemic disadvantages [5].

This brief comparison of the strengths and weaknesses in freight rail systems is intended to show that - under the current structure of effect in supply and demand behaviour in the transport market - the advantages of rail systems for a customized service offer cannot be made applicable. Offers from players in railfreight transport systems need to be based on the system's strengths in the future; weaknesses are to be perceived as opportunities for the whole system [6].

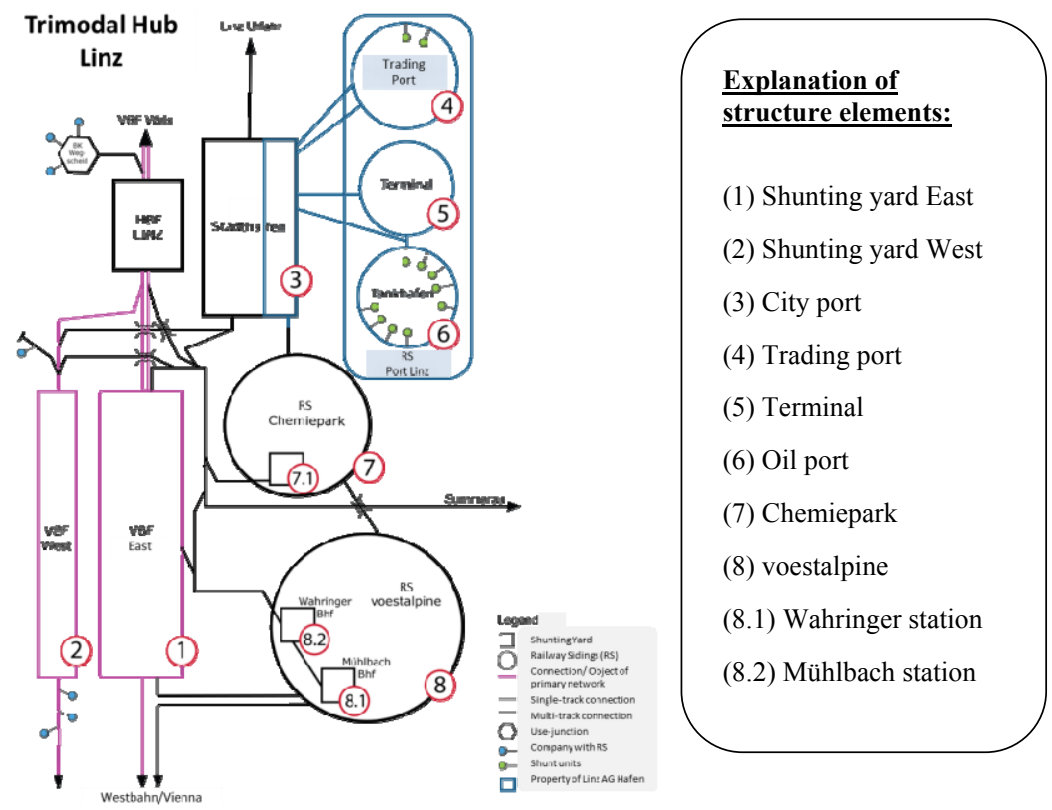

Figure 1: Trimodal junction Linz.

That also applies for the large rail-freight junction in Linz, which is historically grown and intimately linked with the existing structures related to local property and infrastructure. As for the definition of initial system boundaries as well as for better understanding, the given trimodal junction is illustrated in Figure 1. The trimodal transport junction in Linz consists of several railway sidings and shunting yards, one container terminal, a trading port and a tank farm with necessary handling facilities and warehouses for combined and multimodal transports on rail, road and water. The underlying work focuses on the rail system, representing the initial development context.

Railway sidings, tracks, shunting yards, shunt terminal, hump yard and transfer stations of the system in Linz are displayed and show the current system structure. 
At the shunting yard east, all trains are grouped according to their final destination and the formation of primary (trans-regional) and secondary (regional) train groups are realized. All single wagon transports are processed within this shunting yard and are supplied to the concerned railway sidings. Grouped wagons are collected in the sidings. Through the selection of the hump yard the wagons are combined and formed into the ranking group. The arranged wagon groups are further formed into provided directional tracks, to be available for outbound processing.

On a total of $63 \mathrm{~km}$ of track length, the junction Linz actually offers access to the retail infrastructure network for 18 companies, for a total of 1.86 million tons of loading volume in 2012 onto the rail network. The container terminal is a central component in this structure: with an annual volume of 790.000 tons in 2012 , it contributed $42.5 \%$ to the total volume of the junction. Ranked in the Top 3 of freight junctions in Austria, the junction Linz is given significant priority for the future.

\section{Related problem description}

The optimization of node systems in the rail-freight transport business is - due to the prevailing system complexity in general - extremely difficult. Because of the involvement of three rail transport undertaking companies within the given rail-freight junction (RCA, LogServ and Wiener Lokalbahnen), high complexity is a consequential result [7]. Various transport and cargo handling equipment, various interrelated information flows and applied information and communication technologies within existing systems are difficult to be depicted holistically. Problems within the junction operations and processes as well as resource allocation are perceived; the actual causing effects can often not be identified.

Therefore the related problem area comprises processes/operations (incl. the role of the stakeholders) on the one hand and the use of resources (e.g. infrastructure, operating resources and staff) on the other [8].

The main processes/operations at the multimodal rail-freight junction Linz allied to the customer offering - are divided into "block-train transport", "singlewagon transport" and "combined freight transport". Additional operations on the trimodal hub consist of "intermodal transport", "truck transport" and "inland waterway transport". These main product types (described in Table 1) need to be aligned with all operations to ensure maximum customer satisfaction:

Aside from these product types, accompanying service- and informationprocesses as main logistics processes in the rail-freight junction are set to bundle wagons within the junction. Collecting, shunting and distributing processes for optimized utilization of wagons or wagon groups require a well-coordinated use of resources. Threatening resource bottlenecks mostly relate to (1) nonavailability of wagon resources, (2) maintenance activities (repairs of locomotives, spare parts orders, cleaning processes in freight wagons) (3) the provision of cargo handling areas and handling-equipment, (4) the removal 
Table 1: Main product/process types.

\begin{tabular}{|l|l|}
\hline $\begin{array}{l}\text { Product/process type in } \\
\text { junction }\end{array}$ & Description \\
\hline Block train transport & $\begin{array}{l}\text { Block train transport is in particular suitable for } \\
\text { transports over long distances. Core feature is the } \\
\text { transportation of bulk shipments from one same } \\
\text { forwarding station to the same end terminal, } \\
\text { without interruption. }\end{array}$ \\
\hline Single wagon transport & $\begin{array}{l}\text { With single wagon transport, large state-owned } \\
\text { railway companies supply the domestic area with } \\
\text { rail services. Its essential elements are the } \\
\text { collection and distribution of loaded wagons to } \\
\text { the customer and concurrently delivery of } \\
\text { empty wagons, } \\
\text { - empty wagon provision from multiple railway } \\
\text { sidings and defined collection and } \\
\text { - formation of outbound group trains starting } \\
\text { from one shunting yard towards the next. }\end{array}$ \\
\hline Intermodal transport & $\begin{array}{l}\text { An operation that describes the formation of } \\
\text { intermodal transport chains, in which goods are } \\
\text { moved from source to destination through } \\
\text { technical and organizational interconnected } \\
\text { operations. With the use of (standardized) } \\
\text { loading units (e.g. containers), grouped transport } \\
\text { chains the best possible utilization can be } \\
\text { realized. }\end{array}$ \\
\hline $\begin{array}{l}\text { Inland } \\
\text { transport }\end{array}$ & $\begin{array}{l}\text { Logistics services as land transport by truck - } \\
\text { ideally used for pre-/on-carriage, short transport } \\
\text { distances and transport distances in the main } \\
\text { carriage - are perceived as the main service } \\
\text { competitor of single-wagon-transport. }\end{array}$ \\
$\begin{array}{l}\text { Typically part of the combined transport process, } \\
\text { the waterway-transport option stands for a } \\
\text { particular additional or more often alternative } \\
\text { mode of transport (dependent on substratum) in } \\
\text { trimodal transportation hubs, virtually } \\
\text { predestined for (inbound) bulk shipments. }\end{array}$ \\
\hline Road (Truck) transport
\end{tabular}

process of faulty trains from the network as well as (5) the organization of preand on-carriage onto other modes.

In rail-freight transport and its junctions, network and wagon loads are extremely important due to the high investment intensity. An efficient deployment of personnel, a maximum utilization of trains and the use of the rail 
infrastructure and capacities are among the superficial stakeholder tasks in railfreight junctions.

The solution scope within the given rail-freight junction is seen in the following dimensions:

- Reduction of bottlenecks (infrastructure, personnel) through cooperative measures and potentially cooperative organizational units (for balancing demand and available capacity).

- Demand-related time-table adjustments (train compositions, wiring paths, time slots of trains).

- Operational management of capacity through timely information use.

- Identification of modal shift potential - from road (truck) to rail.

- Proposals for limited but meaningful infrastructure expansion measures.

\section{Optimisation approaches}

Main goal of the optimisation is to operate the junction on a co-operative way to ensure a higher common benefit for all stakeholders. To generate successful solutions a systemic approach is needed. For this purpose based on the research work within the solution scope two corresponding optimization approaches represent the most convenient way to match stakeholder demands with the best results, ensuring optimal use of the involved player's time, operating resources and facilities as well as the efficient use of the whole rail infrastructure. The cooperative management and operation of the junction is based on the overlying goal of utility maximization from the perspective of the involved stakeholders (shipper, forwarder etc., ergo "business view") and the business location ("economics view").

The identified optimisation approaches, also referred to as enabler of optimisation, are:

\subsection{Forming a "co-operative junction"}

To operate the specific junction on a co-operative way underlying organizational structures are needed [9], (1) for the value added oriented vertical and horizontal integration in reasonable areas, (2) to establish co-operative operational units like resource and personal pools and (3) for the coordinated use of infrastructure agreed upon between the involved players. As a result of this approach a contracted utilization concept enables the collaborative functioning of the junction.

A utilization concept typically consists of structures, processes and tools for

- cooperative transport planning and execution,

- the efficient use of infrastructure,

- empty wagon management,

- realizing modal-shift potentials,

- $\quad$ optimising block train utilization and

- $\quad$ risk management (back-up processes). 
For a joint examination of utilization concepts software-based prototypes can contribute significantly for implementing efficient operating co-operative structures by simulation.

\subsection{Prototype based analysis}

Prototype based simulation allows to analyze and virtualize selected aspects and characteristics of the junction and therefore to estimate various scenarios within the defined areas of application (see below). Using the example of the junction Linz (Upper Austria) the developed prototype is a rule-based software application to analyze the functioning of the shunting yard east as well as other selected aspects of the junction (shippers etc.). By importing generic data and using a close to reality control system with defined rules for the discrete process steps, the prototype can be used within different areas of application.

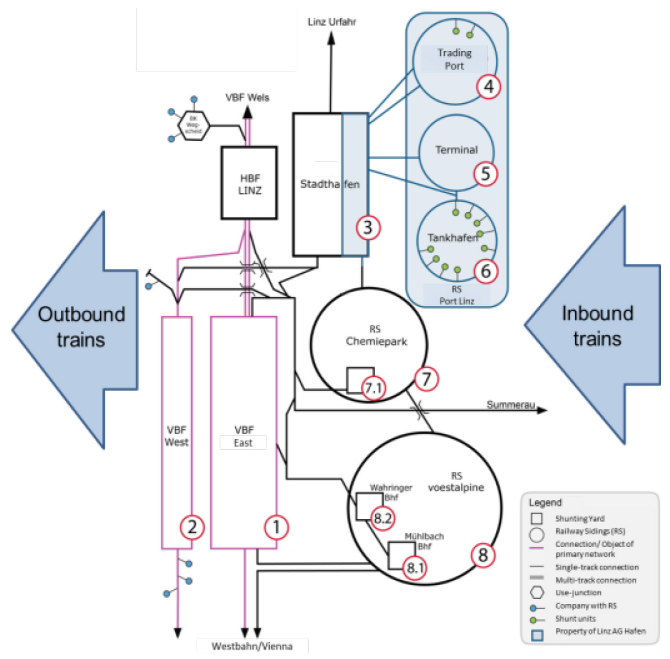

Figure 2: Infrastructure utilization.

Areas of application for optimisation scenarios (actual and optional status):

- Scenario: yard validation

- Simulation to analyze the actual status of the shunting yard (virtualization). Validation is also needed to test the sound functioning of the prototype.

- Scenario: capability of shunting yard

- Simulation of the actual status by adoption of the opening hours of the shunting yard. Based on variable opening hours the systemic changes can be analyzed regarding the throughput time of the wagons and the number of manipulated wagons per week.

- Simulation of the actual status by adoption of the control rules (based on defined measures) to boost the degree of capacity utilization. 
- Simulation of the systemic impact reached by technologization of the main infrastructure components (e.g. hump yard) regarding throughput time and labour utilization (optional status).

- Scenario: changes in transport volume (optional status)

- Simulation of effects and systemic changes within the junction caused by modal shift from truck to rail and/or increasing volumes of the resident shippers.

- Simulation of systemic changes evoked by optimising the yard train schedule (ergo adoption of the control rules for the departure yard).

The combination of the mentioned optimization approaches allows choosing an optimization strategy that best fits to the requirements of the involved stakeholders.

Table 2: Prototype functions for planning and analysing processes.

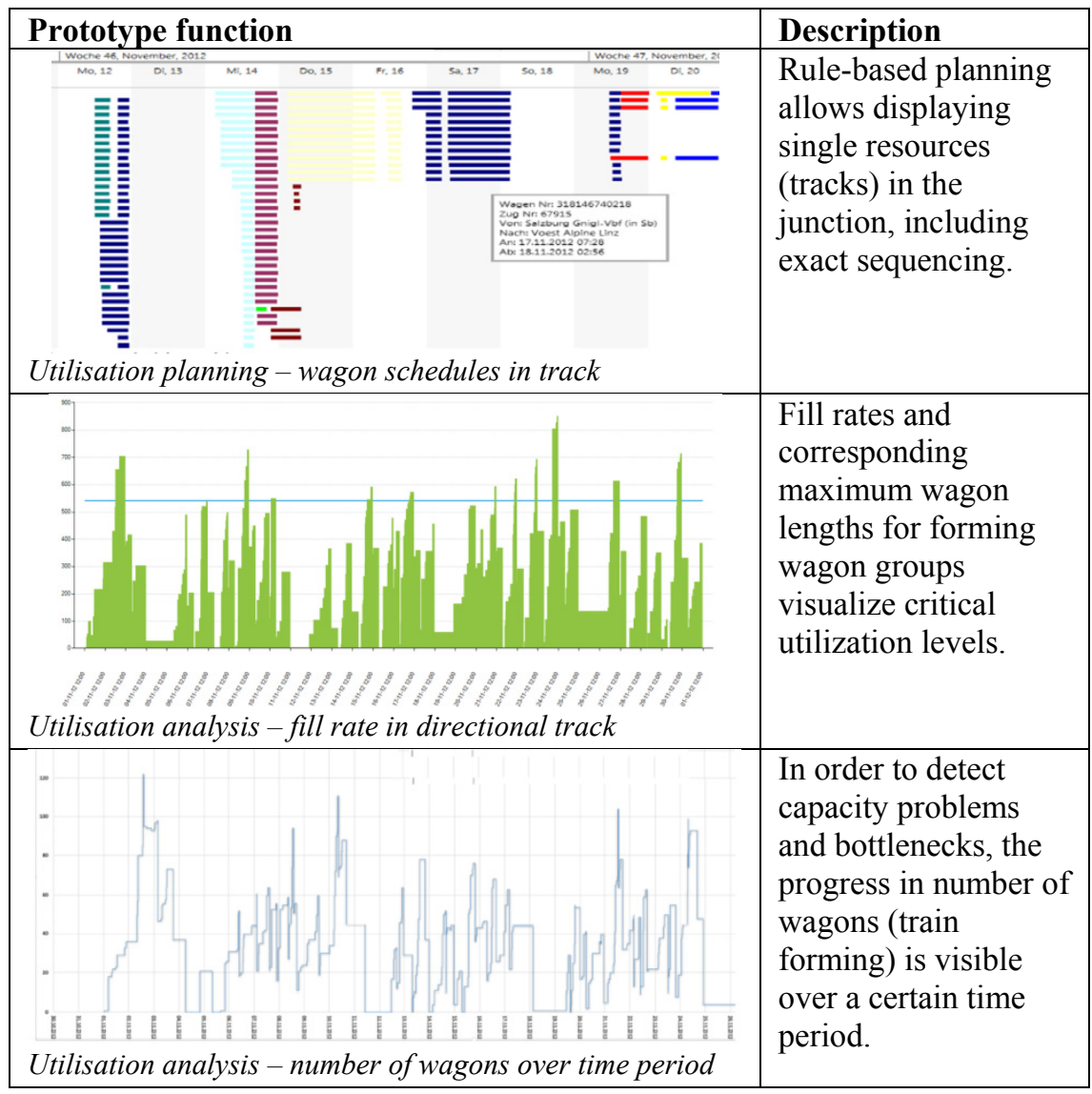




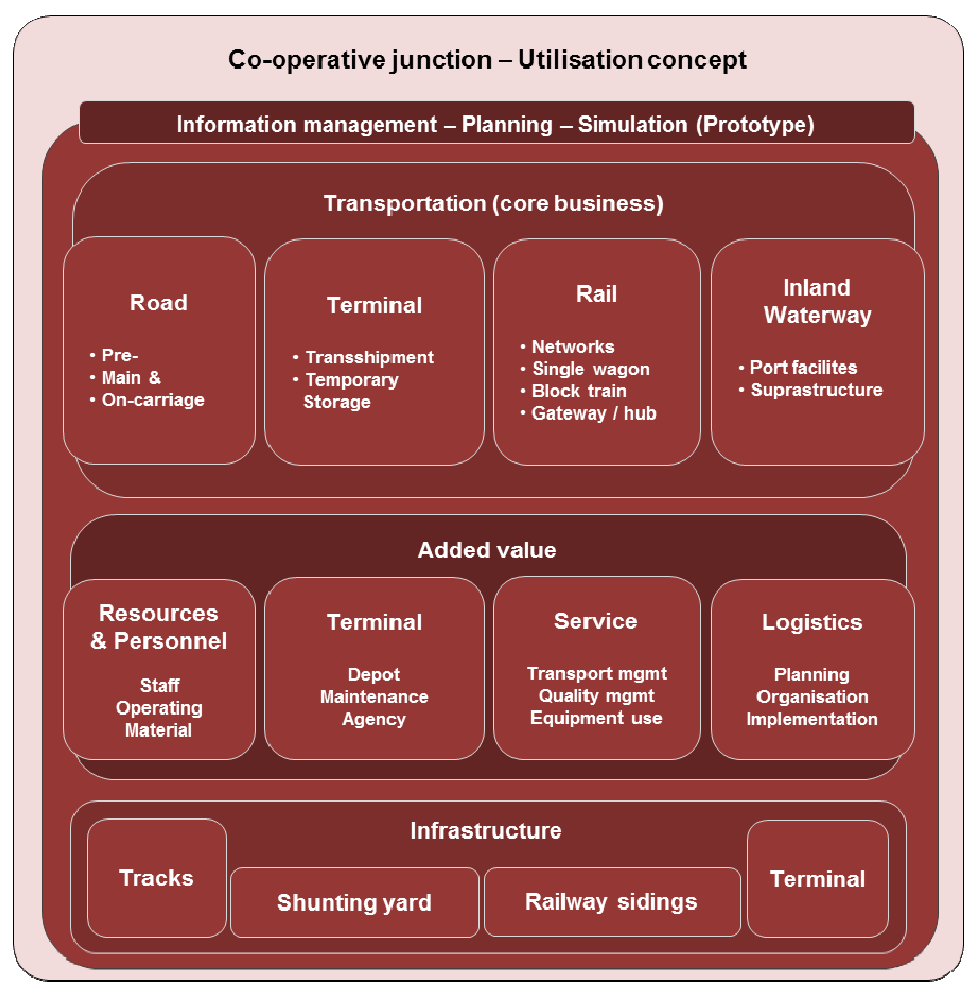

Figure 3: The utilisation concept for a co-operative junction structure.

\section{Results and conclusion}

As already stated above, the main goal of the optimisation is to operate the junction on a co-operative way to ensure a higher common benefit for all stakeholders. But the optimization of historically grown rail-freight junctions is a challenging and highly complex task. Because of the involvement of multiple transporting, transshipping and shipping companies, various equipment and information flows as well as information and communication technologies, all single components have to be seen as one communicating system. To fulfil the needs of all involved players and operate the junction as efficient as possible the involved stakeholders, relating processes and infrastructure components have to be merged and handled as a unit. To conclude from the results: In order to implement the co-operative use of the infrastructural (for efficient infrastructure use) and operating resources (cross-company cooperation regarding operating resources and staff) and on this basis optimize logistics and transport processes, common organizational structures are needed, respectively indispensable.

Figure 3 shows all involved components of a utilization concept. The merging framework consists of common information and planning structure with a simulation tool (prototype) for optimising. 
Critical factors for the success of co-operative concepts are [10]:

- short- and long term benefit for all involved stakeholders,

- increasing the competitiveness of all market players ("business view") and of the whole junction ("economic view") and

- preservation and expansion of rail-freight infrastructure (junction has potential for growth).

The stated design recommendations for a co-operative concept in a large railway junction clarify that in these specific models of transport networks of rail freight, further adjustments (involving information management, co-operative planning and simulation activities) are in demand to better meet future customer needs.

\section{References}

[1] Blauwens, G., Vandaele, N., van de Voorde, E., Vernimmen, B. \& Witlox, F., Towards a Modal Shift in Freight Transport? A Business Logistics Analysis of Some Policy Measures 26 (2), pp. 239-251, 2006.

[2] Den Hengst, M., Interorganizational coordination: the role of information technology. In J.W. Konings, R. Konings, H. Priemus \& P. Nijkamp (Eds.): The future of intermodal freight transport: operations, design and policy: Edward Elgar (Transport economics, management, and policy), pp. 252-270, 2008.

[3] Bach, N., Buchholz, W. \& Eichler, B., Geschäftsmodelle für Wertschöpfungsnetzwerke; Gabler Verlag. Wiesbaden, 2010.

[4] Mayer, J., Anforderungen an das System Bahn und Konsequenzen für die Strategie. In D. Lübke, M. Hecht (Eds.): Das System Bahn: Handbuch: Eurailpress, pp. 109-121, 2008.

[5] Notteboom, T., Bundling of freight flows and hinterland network developments. In J.W Konings, R. Konings, H. Priemus \& P. Nijkamp (Eds.): The future of intermodal freight transport: operations, design and policy: E. Elgar (Transport economics, management, and policy), pp. 66$88,2008$.

[6] Jahncke, R., Branchenspezifische Leistungsangebote im Schienengüterverkehr: Motivation, Konzepte und Vorgehensweisen zur Verlagerung von Straßengüterverkehrs auf die Schiene: Dt. VerkehrsVerlag, 2008.

[7] Siegmann, J. \& Jänsch, E., Perspektiven des Systems Bahn. In Dietmar Lübke, M. Hecht (Eds.): Das System Bahn: Handbuch: Eurailpress, pp. 625-633, 2008.

[8] Fischer, T., Geschäftsmodelle in den Transportketten des Europäischen Schienengüterverkehrs. Eine Typologisierung von Eisenbahnverkehrsunternehmen unter besonderer Berücksichtigung der Anbieterstruktur im deutschsprachigen Raum. WU Wien, Institut für Transportwirtschaft und Logistik. Wien, 2008. 
[9] Jensen, A., Designing intermodal transport systems: a conceptual and methodological framework. In J.W. Konings, R. Konings, H. Priemus \& P. Nijkamp (Eds.): The future of intermodal freight transport: operations, design and policy: E. Elgar (Transport economics, management, and policy), pp. 187-205, 2008.

[10] Schneider, J. \& Zatta, D., Internationalisierung im Schienenverkehr. Internationales Verkehrswesen, Vol. 56, 2004. 